\title{
MICRO-HISTÓRIA EM MOVIMENTO
}

\author{
SCOTT, Rebecca J. e HÉBRARD Jean M., Freedom Papers: An Atlantic \\ Odyssey in the Age of Emancipation. Cambridge, MA e Londres: Harvard \\ University Press, 2012. 259 p.
}

\begin{abstract}
Neste livro notável, Rebecca J. Scott zer tais alegações quando eles proe Jean M. Hébrard realizam três conquistas simultâneas. Primeiro, reconstroem com detalhamento impressionante a biografia coletiva de uma família afrodescendente, abrangendo cinco gerações e movimentos da Senegâmbia ao Haiti, Cuba, Estados Unidos, França, México e Bélgica. Em segundo lugar, descrevem os contextos em que esses membros da família viveram, focando nos constrangimentos legais e extralegais sobre as pessoas de cor em uma variedade de lugares e tempos. Finalmente, ao traçar as estratégias ágeis através das quais os membros da família lutaram por liberdade, dignidade e prosperidade em face da escravidão e do racismo, os autores enfatizam o uso da escrita. "Os membros de cada geração", dizem eles aos leitores,

mostraram uma consciência da função crucial dos documentos para fa-

videnciavam para que papéis fossem produzidos: registros eclesiásticos quando levavam uma criança para ser batizada, registros notariais quando registravam um contrato, cartas ao editor quando se envolviam no debate público, correspondência privada ao transmitir as notícias uns aos outros (p. 3).

Os autores caracterizam sua abordagem como "micro-história em movimento" (p. 4). O argumento não é de que a família de seu estudo fosse típica, nem que fosse excepcional. Em vez disso, Scott e Hébrard afirmam que "o estudo de um local ou evento cuidadosamente escolhido, visto bem de perto, pode revelar dinâmicas que não são visíveis através da lente mais familiar da região ou da nação" (p. 5). Neste caso, uma dessas dinâmicas é o movimento: através do mar do Caribe, do Golfo do México e do Oceano Atlântico. E, em cada local,
\end{abstract}


a história ilumina algumas das maneiras como as pessoas conseguiram, em condições que eles não criaram, usando o sistema tal como era, abrir fendas grandes o suficiente para que nelas coubessem. Ocasionalmente, esta luta se transformou no tipo que chamaríamos de luta política; muitas vezes tratava-se de apostas na prosperidade, autonomia e dignidade em um âmbito muito mais pessoal ou familiar.

Como o título indica, a escrita é o eixo deste livro. Por um lado, ela foi o mecanismo pelo qual, uma e outra vez, os membros desta família trabalharam para alcançar e salvaguardar sua liberdade. Por outro, os fragmentos de papel que seus personagens deixaram para trás são a trilha que os autores rastrearam meticulosamente para descobrir e contar suas histórias. O trabalho de detetive histórico aqui é um tour de force. É também uma parte vital da narrativa, começando com a descoberta por Rebecca Scott de uma carta escrita em 1899 por um comerciante de charutos de Antuérpia, chamado Édouard Tinchant, ao general cubano Máximo Gómez. No curso de um pedido de permissão para usar a imagem de Gómez em uma marca de charutos, Tinchant narrou sua própria história familiar:

Nascido na França em 1841, sou de ascendência haitiana [...] instalado em Nova Orleans após a Revolução, o meu pai deixou [...] Louisiana pela França com o único objetivo em vista de educar seus seis filhos em um país sem leis infames ou preconceitos estúpidos que pudessem impedi-los de se tornarem homens (p. 2).

Seguindo a pista deste primeiro e tentador pedaço de papel, Scott e Hébrard vasculharam arquivos em sete países e conseguiram reconstruir não só a versão mais completa da narrativa que Tinchant fez a Gómez, mas uma história de família muito maior, embutida numa mutante dinâmica da raça, da escravidão e da lei ao longo de quase dois séculos.

A ancestral fundadora da família Tinchant nas Américas foi uma mulher descrita em um documento de alforria de 1803 como "Rosalie, Négresse de nation Poulard". Embora tais descritores étnicos não fossem geograficamente precisos, eles são sugestivos. Em São Domingos do século XVII, "Poulard" indicava origem na Senegâmbia. Com base em uma reconstrução atraente da dinâmica africana, Scott e Hébrard conjecturam que Rosalie falasse a língua pulaar (fula) e tivesse sido capturada no vale do rio Senegal, ou perto, incluindo uma região conhecida como Futa Toro. Ali, em meados da década de 1770 , uma revolução islâmica depôs a aristocracia guerreira e introduziu novas restrições ao comércio de escravos. $\mathrm{O}$ iman proibiu a venda de muçulmanos como escravos e impediu comerciantes franceses de adquirir cativos em seus domínios. No entanto, líde- 
res vizinhos e adversários continuaram a atacar seu território e a fazer prisioneiros para venda no além mar. Um desses pode ter sido a jovem mais tarde conhecida como Rosalie, cuja experiência, na Senegâmbia, pode têla familiarizado não apenas com a agitação revolucionária, mas também com o poder da palavra escrita. Muçulmanos do Oeste africano reconheciam um alto valor na aprendizagem e na alfabetização, e muitos carregavam amuletos contendo versos escritos em minúsculos pedaços de papel que acreditavam ter poder de proteção.

No final dos anos 1780 ou no início dos anos 1790, Rosalie desembarcou de um navio negreiro em SaintDomingue. Na cidade sulista de Jérémie, ela foi comprada por Marthe Guillaume, preta livre e próspera comerciante. Na década seguinte, revolta massiva de escravos, invasão estrangeira e a guerra pela independência transformaram São Domingo francês no Haiti independente, mas o status de Rosalie não mudou tão decisivamente. Embora comissários franceses tivessem anunciado a abolição da escravatura em 1793, Jérémie foi invadida por tropas inglesas que apoiavam os senhores de escravos. Enquanto isso, Rosalie começou a viver com um colono francês chamado Michel Vincent e deu à luz seus filhos. Em 1795, Mme. Guillaume redigiu um documento de alforria para Rosalie, mas fracassou em sua tentativa de tê-lo certificado pelo comandante britânico local. Nesta e em muitas outras ocorrências, Rosalie e sua descendência ficaram no limbo legal, não exatamente escravos, mas não totalmente livres. Da mesma forma, quando em 1799 Rosalie e Michel Vincent levaram seu bebê Élisabeth para ser batizada, eles não eram casados, mas Vincent reconhecia a paternidade, dando à filha seu sobrenome, se não a plena legitimidade. Quatro anos mais tarde, em meio à convulsão da invasão francesa do Haiti e na esperança de sair da ilha para a França, Vincent criou um documento de alforria para Rosalie e seus quatro filhos. Tecnicamente, eles já eram livres, porque a Revolução Haitiana trouxera a emancipação geral, e de qualquer modo, eles não eram propriedades de Vincent. Mas o casal Vincent aparentemente apostava na segurança, imaginando que se a tentativa francesa de voltar a impor a escravidão fosse bem sucedida, o documento poderia ser útil.

Em 1803, Rosalie e sua filha Élisabeth, e talvez seus três filhos mais velhos, juntaram-se a outros que fugiam da guerra que eventualmente traria a independência haitiana. Dirigiram-se a Santiago de Cuba, onde Michel Vincent já havia chegado. Lá, o francês, moribundo, registrou um testamento, três dias depois, Rosalie solicitou às autoridades o registro de seus documentos de liberdade, na es- 
perança de que eles iriam protegê-la sob a Coroa espanhola em uma sociedade escravista. Mas Cuba mostrou ser apenas um refúgio temporário. Após o estouro da guerra entre a França e a Espanha, em 1808, as autoridades cubanas expulsaram todos os refugiados "franceses" vindos de São Domingos. A Louisiana oferecia o recurso de uma substancial população de língua francesa e, para senhores de escravos refugiados, a suposição de que seus direitos de "propriedade" seriam mantidos. Para a africana Rosalie, no entanto, o risco de re-escravização era grande demais para suportar. Ela mandou a filha Élisabeth para Nova Orleans com a madrinha da menina, a viúva Aubert, e seu consorte, um carpinteiro belga chamado Lambert Detry. Mas a própria Rosalie voltou ao agora independente Haiti.

Rosalie deve ter calculado que sua filha estava diante de um futuro mais seguro na Louisiana, com a modestamente próspera viúva Aubert, do que com ela de volta ao Haiti. De fato, na sociedade escravista de Nova Orleans, a viúva Aubert e Élisabeth mantiveram sua condição de pessoas livres de cor; e o casal que cuidava da filha de Rosalie se estabeleceu com o dinheiro e os escravos trazidos de Cuba. Élisabeth cresceu em uma comunidade de afrodescendentes livres, que cuidadosamente protegiam seu status, mesmo se tivessem vínculos tanto com escravizados quanto com alguns brancos. Em 1822, Élisabeth Vincent casou com Jacques Tinchant, filho de uma mulher de cor livre e de um francês, ambos originários de SaintDomingue. Tinchant sustentava sua família comprando, construindo e, em seguida, vendendo lotes de terra na periferia da cidade que crescia. Élisabeth deu à luz seis filhos, todos batizados na catedral da cidade. Enquanto isso, o status de Élisabeth enquanto filha legítima de seu pai, o que reforçava a sua respeitabilidade, foi assegurado quando a idosa Rosalie chegou a Nova Orleans com a certidão de batismo de Élisabeth, na qual Michael Vincent reconhecia a paternidade perante o tabelião. Neste ato, como em muitos outros, Rosalie contou com a força da palavra escrita e oficialmente registrada como uma salvaguarda no perigoso mundo da supremacia branca e da escravidão.

A escrita tornou-se mais explicitamente política na história familiar na geração seguinte, embora não imediatamente. Em 1830, enquanto a família Tinchant crescia, restrições legais e sociais espremiam as pessoas livres de cor na Louisiana. Em 1840, Jacques e Élisabeth venderam a maior parte de suas propriedades em Nova Orleans, arrumaram suas quatro crianças e seguiram os pais de Jacques para a região dos Baixos Pirineus na França. A família comprou uma grande fazenda, contratou 
trabalhadores e mandou os filhos para a escola. Quando as convulsões políticas de 1848 resultaram na abolição da escravatura na nova República Francesa e suas colônias, o filho dos Tinchant, Joseph, tinha terminado a escola e se mudado para Paris. Quando Louis-Napoleon Bonaparte deu o golpe de Estado de 1851, Joseph Tinchant havia partido para Nova Orleans para se reunir a seu irmão mais velho, Louis, que deixara para trás para cuidar dos negócios da família. Joseph e Louis começaram uma manufatura de charutos, aproveitando o capital de seus pais para expandir seus negócios ao longo dos anos.

Durante as décadas 1850 e 60, os negócios da família estavam crescendo. Louis mudou-se para Antuérpia para criar uma conexão europeia para o que estava se tornando uma operação comercial trans-continental. Seus pais e alguns membros da família os seguiram da França até ali, enquanto os irmãos Pierre e Jules se reuniram a Joseph em Nova Orleans. Quando a Guerra Civil americana começou, Joseph Tinchant tentou manter seu negócio de charuto na Louisiana governada pelos confederados, mas os irmãos Jules e Pierre partiram para tentar a sorte em Veracruz, México. Enquanto isso, o mais novo dos Tinchant, Édouard, deixava Antuérpia em meio a escândalos pessoais e chegava a Nova Orleans mais ou menos ao mesmo tempo em que as forças da União começavam a ocupação da cidade. Joseph organizou apoio militar à União, e em 1863 serviu no rapidamente mobilizado regimento dos homens de cor para ajudar a defender a cidade contra um possível ataque confederado. Mas foi Édouard quem emergiu como a voz política radical da família. Em uma série de cartas para um jornal de Nova Orleans, em 1864, ele combateu a emigração para o México, que outro colunista defendia em razão de que lá as perspectivas eram melhores do que na Louisiana para os americanos de cor. Enquanto Édouard enchia as colunas do jornal com exortações para a população de ascendência africana ficar e ajudar a construir uma sociedade mais igualitária, seu irmão Joseph e sua família preparavam a viagem para o México.

Édouard Tinchant seguiu seu próprio conselho para ficar na Louisiana, ali se estabelecendo e se tornando diretor de uma escola para crianças negras. Durante a Reconstrução, ele foi eleito delegado à convenção que iria escrever a nova constituição do estado da Louisiana. Como parte de uma coalizão de ex-escravos, homens livres de cor, unionistas brancos nortistas e locais, Tinchant pressionava para incluir na nova legislação estadual não somente a igualdade de direitos civis e políticos para todos os cidadãos do estado, mas também "direitos públicos", incluindo a igualda- 
de de acesso ao transporte e moradia. Além disso, sem dúvida ciente da precária condição jurídica de suas duas avós em casamentos informais e interraciais, ele propôs que a Convenção assegurasse a proteção legal de todas as mulheres, independentemente da cor ou status, permitindo-lhes processar por violação de promessa de casamento. Embora esta disposição não fosse ratificada, Tinchant e os outros delegados produziram uma das mais radicais e igualitárias constituições estaduais no período pós-Guerra Civil. Contudo, em meados da década de 1870, a Reconstrução estava concluída, uma nova Constituição, racista, tinha sido ratificada e a escola de Édouard Tinchant fechado suas portas. Édouard e sua esposa decidiram tentar a sorte em outro lugar e se mudaram para Mobile, Alabama.

Enquanto isso, o irmão de Édouard, Joseph Tinchant, que se mudara com sua família para o México, labutava no negócio de tabaco da família. Em meados da década de 1870 , sua família migrou novamente, desta vez para se juntar aos parentes de Antuérpia. Lá, Joseph Tinchant surgiu como Don José Tinchant y Gonzales, acrescentando, no estilo mexicano, o sobrenome da família de sua esposa ao seu próprio. Embora seu produto fosse então feito na Europa, a marca Tinchant aludia a seu tempo de México e a vagas conexões com Cuba, com a finalidade de co- mercializá-los como se fossem os caros charutos conhecidos como Havanas. Tal movimento destaca um tema-chave desta seção do livro: a autoconsciência dos Tinchant na formação de suas identidades públicas, cientes de como o status poderia alternar entre graus de liberdade, diversas categorias de cor, diferentes nacionalidades (ou, às vezes, a falta de identidade nacional) e classes sociais desiguais. De fato, como os Tinchant bem sabiam, o status às vezes podia situar-se entre uma e outra categoria social, e fora por meio de peças jurídicas de papel que os membros da família tinham afirmado e assegurado seus direitos e atribuições.

Os irmãos Tinchant e suas famílias acabaram todos na Antuérpia no final do século XIX, prosperando como fabricantes de charutos. Mas sobre suas nacionalidades exatas restava alguma dúvida. Joseph se esforçava para alcançar a cidadania belga definitiva, mesmo que, em seu comércio, se intitulasse mexicano com laços com Cuba. Édouard descrevia a si mesmo como cidadão americano com nacionalidade francesa, mesmo após uma década de vida na Bélgica. Com todos os Tinchant, e em grande parte independentemente da sua nacionalidade, a questão da cor da pele e suas implicações de afrodescendência e sugestões de escravidão, foi silenciada desde que sua respeitabilidade permanecesse intacta. Ainda 
assim, quando Édouard Tinchant escreveu ao general cubano Máximo Gómez pedindo permissão para usar sua imagem em charutos, ele invocou sua ascendência africana e haitiana, a luta de sua família contra a supremacia branca, e sua fidelidade política ao republicanismo não racial.

Duas gerações mais tarde, na história final de Freedom Papers, outro Tinchant continuou a lutar. Em 1937, Marie-José Tinchant, de 20 anos de idade (neta de Joseph Tinchant), e seu noivo belga viajaram até Londres para se casar. Os pais dele estavam tentando impedir o casamento porque, como disse a noiva a um repórter de jornal: "Eu sou de família honrada, mas eu não sou uma menina branca, de modo que seus pais estão tentando impedir nosso casamento" (p. 174). O casal conseguiu se casar, mas isso não findou a saga de MarieJosé. Em maio de 1940, a invasão nazista da Bélgica começou. MarieJosé trabalhou clandestinamente para a Resistência e, finalmente, foi detida como presa política. No campo de concentração de Ravensbrück, ela e outros prisioneiros se tornaram trabalhadores escravos. Marie-José Tinchant foi morta em uma câmara de gás em 1945. Ao contabilizar os mortos após a guerra acabar, no entanto, as autoridades belgas negaramlhe o título póstumo de prisioneira política. Em vez disso, elas concluí- ram, apesar de evidências em contrário, que ela havia sido presa por um motif racial - um "motivo racial" e, portanto, fora uma vítima da guerra, não uma heroína.

De maneira pungente, a narrativa do livro termina como começa: com o cativeiro, a escravidão e a inscrição de categorias racializadas de status e de direitos. Este livro pode de fato ser lido como um relato implacável da persistência da supremacia branca e da precariedade da liberdade, que muda, mas persiste ao longo de gerações. Mas Scott e Hébrard provavelmente discordariam dessa visão. O que eles repetidamente enfatizam é a navegação determinada e muitas vezes brilhante dos indivíduos por entre as estruturas opressivas com que eles e seus familiares foram confrontados. Rosalie Vincent, Élisabeth Tinchant, Édouard Tinchant e, sem dúvida, incontáveis outros personagens elaboraram estratégias e documentos para conferir status e moldar identidades, em face dos, por vezes, enormes obstáculos criados pelos sistemas e práticas jurídicas da supremacia branca. Freedom Papers é um testemunho não só da habilidade em condições opressivas, mas, nas mãos de Scott e Hébrard, a trilha de papel para uma fascinante saga familiar.

Lisa A. Lindsay lalindsa@email.unc.edu University of North Carolina Tradução de Mariângela Nogueira 